\title{
Breast implant-associated anaplastic large-cell lymphoma (BIA-ALCL)
}

\section{Jun-Ho Lee}

Department of Plastic and Reconstructive Surgery, Yeungnam University College of Medicine, Daegu, Korea

Received: October 15, 2020

Revised: November 22, 2020

Accepted: December 1, 2020

Corresponding author:

Jun-Ho Lee, MD

Department of Plastic and

Reconstructive Surgery, Yeungnam

University College of Medicine, 170

Hyeonchung-ro, Nam-gu, Daegu

42415 , Korea

Tel: +82-53-620-3480

Fax: +82-53-626-0705

E-mail: junojunho@gmail.com
Breast implant-associated anaplastic large-cell lymphoma (BIA-ALCL) is a rare T-cell non-Hodgkin lymphoma characterized as CD30 positive and anaplastic lymphoma kinase (ALK) negative. In 2016, the World Health Organization declared BIA-ALCL as a new disease entity. The first case of BIA-ALCL was reported in 1997, and as of July 2019, the United States Food and Drug Administration had cited a total of 573 United States and global medical device reports of BIA-ALCL, including 33 deaths. In all clinical case reports, except for those with unknown clinical history, the patient had received at least one textured surface breast implant. Although the etiology is not yet clear, chronic inflammation has been proposed as a potential precursor to tumorigenesis. The most common presentation of BIA-ALCL is peri-implant fluid collection following aesthetic or reconstructive implantation with textured surface breast implants. It can be accompanied by breast swelling, asymmetry, pain, skin lesions, lymphadenopathy, and B-type symptoms. Most cases are detected on average 7 to 10 years after implantation. Diagnostic specimens can be obtained with fine-needle aspiration or biopsy. BIA-ALCL is CD30 positive, epithelial membrane antigen positive, and ALK negative. It can be cured with complete surgical excision at the T1-T3 stage.

Keywords: Anaplastic large-cell lymphoma; Breast implantation; Breast implants

\section{Introduction}

In August 2019, the Ministry of Food and Drug Safety of Korea (MFDS) ordered to stop using and selling Biocell textured breast implants (Allergan Inc., Irvine, CA, USA). This decision came after the first case of breast implant-associated anaplastic lymphoma (BIA-ALCL) in Korea was reported on August 14, 2019 [1]. As of now, three cases of BIA-ALCL have been reported in South Korea [2]. BIA-ALCL is an uncommon T-cell non-Hodgkin lymphoma characterized as $\mathrm{CD} 30$ positive and anaplastic lymphoma kinase (ALK) negative. Primary lymphoma of the breast is very rare, accounting for only $0.12 \%$ to $0.53 \%$ of all malignant breast tumors, approximately $2.2 \%$ of extranodal lymphomas, and less than $1 \%$ of all non-Hodgkin lymphomas. Over the past decades, there has been increasing doubt about an etiologic link between breast implants and the development of ALCL. In January 2011, the United States (US) Food and Drug Administration (FDA) stated the relationship between BIA-ALCL and breast implants for the first time as "Although ALCL is extremely rare, the FDA believes that women with breast implants may have a very small but increased risk of developing this disease in the scar capsule adjacent to the implant" [3]. In 2016, the World Health Organization declared BIA-ALCL as a new disease entity [4].

\section{Epidemiology}

The first case of BIA-ALCL was reported by Keech and Creech [5] in 1997, and by July 2019, the FDA updated a total of 573 US

Copyright (C) 2021 Yeungnam University College of Medicine

This is an Open Access article distributed under the terms of the Creative Commons Attribution Non-Commercial License (http://creativecommons.org/licenses/by-nc/4.0/) which permits unrestricted non-commercial use, distribution, and reproduction in any medium, provided the original work is properly cited. 
Table 1. Summary of US and global deaths reported in MDRs received as of July 6, $2019(n=33)$

\begin{tabular}{|c|c|c|c|}
\hline \multirow{2}{*}{\multicolumn{2}{|c|}{ ALCL deaths from MDRs and literature reported as MDRs }} & \multicolumn{2}{|c|}{ Deaths through $7 / 6 / 2019(n=33)$} \\
\hline & & $\mathrm{n}$ & $\% 0^{b)}$ \\
\hline \multirow[t]{3}{*}{ Age at time of diagnosis (yr) } & Median & 52 & \\
\hline & Range & $37-83$ & \\
\hline & Not specified (no. of reports) & 13 & 39 \\
\hline \multirow[t]{3}{*}{ Time from the last implant to diagnosis (yr) } & Median & 9 & \\
\hline & Range & $1-20$ & \\
\hline & Not specified (no. of reports) & 23 & 70 \\
\hline \multirow[t]{3}{*}{ Implant surface } & Textured & 15 & 48 \\
\hline & Smooth ${ }^{\text {a) }}$ with history of textured & 1 & 3 \\
\hline & Not specified & 17 & 48 \\
\hline \multirow[t]{3}{*}{ Implant fill } & Silicone & 14 & 42 \\
\hline & Saline & 8 & 24 \\
\hline & Not specified & 11 & 33 \\
\hline \multirow[t]{3}{*}{ Reason for implant } & Reconstruction & 5 & 15 \\
\hline & Augmentation & 17 & 52 \\
\hline & Not specified & 11 & 33 \\
\hline \multirow[t]{6}{*}{ Clinical presentation (breast) } & Seroma & 6 & 18 \\
\hline & Breast swelling/pain & 3 & 9 \\
\hline & Capsular contracture & 1 & 3 \\
\hline & Peri-implant mass/lump & 13 & 39 \\
\hline & Others & 7 & 21 \\
\hline & Not specified & 7 & 21 \\
\hline \multirow[t]{3}{*}{ Anaplastic lymphoma kinase } & Positive & 0 & 0 \\
\hline & Negative & 12 & 36 \\
\hline & Not specified & 21 & 64 \\
\hline \multirow[t]{3}{*}{ CD30 status $^{\mathrm{d})}$} & Positive & 12 & 36 \\
\hline & Negative & 0 & 0 \\
\hline & Not specified & 21 & 64 \\
\hline \multirow[t]{3}{*}{ Implant manufacturer } & Allergan & 12 & 36 \\
\hline & Mentor & 1 & 3 \\
\hline & Unknown & 20 & 61 \\
\hline \multirow[t]{3}{*}{ Reporter country: US or OUS } & US & 12 & 36 \\
\hline & OUS & 21 & 64 \\
\hline & Not specified & 0 & 0 \\
\hline
\end{tabular}

US, the United States; MDR, medical device report; ALCL, associated anaplastic large-cell lymphoma; OUS, outside the US.

a) Includes one case of B-cell lymphoma. ${ }^{b}$ Percentage in terms of the total 33 deaths. There are no reports of deaths associated with tissue expanders. ${ }^{c}$ MDRs sometimes list more than one clinical presentation, e.g., seroma and peri-implant mass/lump, in which two presentations were counted. ${ }^{\text {d) }} \mathrm{CD} 30$ is a cell membrane protein associated with diagnosis of classic Hodgkin's lymphoma and breast implant-ALCL. ${ }^{\text {e) } U S / O U S ~ i s ~ c o u n t e d ~ a s ~ t h e ~ c o u n t r y ~ r e p o r t e d ~}$ in the narrative or the recorded reporter's country in the MedWatch form.

Adapted from the materials of U.S. Food and Drug Administration [6].

and global medical device reports of BIA-ALCL, including 33 deaths (Tables 1,2) [6]. Because of its rare occurrence, it is difficult to determine the exact prevalence of BIA-ALCL. In 2008, de Jong et al. [7] published the first case-control study and reported that the risk of BIA-ALCL development in women with breast implants was 18.2-fold higher than in women who did not have implants (odds ratio, 18.2; 95\% confidence interval [CI], 2.1-156.8).
In 2018, the same group reported the relative risk of BIA-ALCL with breast implants as 421.8 (95\% CI, 526.6-3,385.2) and absolute cumulative risks of 29 per million and 82 per million at 50 years and 70 years, respectively. The estimated prevalence of BIA-ALCL with breast implants in women aged 20 to 70 years was 3.3\% [7]. In 2017, Doren et al. [8] published the first US population-based report demonstrating a significant association between 
Table 2. Summary of US and global data as of July 6, $2019(n=573)$

\begin{tabular}{|c|c|c|c|c|c|}
\hline \multirow{2}{*}{ Unique ALCL cases $^{\text {a) }}$} & & \multicolumn{2}{|c|}{$\begin{array}{l}\text { Cases through } 9 / 30 / 2018 \\
(n=457)\end{array}$} & \multicolumn{2}{|c|}{$\begin{array}{l}\text { Cases through } 7 / 6 / 2019 \\
\qquad(n=573)\end{array}$} \\
\hline & & $\mathrm{n}$ & $\% 0^{b)}$ & $n$ & $\%{ }^{c)}$ \\
\hline \multirow[t]{3}{*}{ Age at time of diagnosis (yr) } & Median & 53 & - & 53 & - \\
\hline & Range & $27-90$ & - & $27-90$ & - \\
\hline & Not specified (no. of reports) & 111 & 24 & 161 & 28 \\
\hline \multirow[t]{3}{*}{ Time from the last implant to diagnosis (yr) } & Median & 9 & - & 8 & - \\
\hline & Range & $0-34$ & - & $0-34$ & - \\
\hline & Not specified (no. of reports) & 110 & 24 & 169 & 29 \\
\hline \multirow[t]{3}{*}{ Implant surface } & Textured & 310 & 68 & 385 & 67 \\
\hline & Smooth & 24 & 5 & $26^{d)}$ & 5 \\
\hline & Not specified & 123 & 27 & 162 & 28 \\
\hline \multirow[t]{3}{*}{ Implant fill } & Silicone & 274 & 60 & 343 & 60 \\
\hline & Saline & 183 & 40 & 197 & 34 \\
\hline & Not specified & 0 & 0 & 33 & 6 \\
\hline \multirow[t]{3}{*}{ Reason for implant } & Reconstruction & 108 & 24 & 115 & 20 \\
\hline & Augmentation & 104 & 23 & 111 & 19 \\
\hline & Not specified & 245 & 54 & 347 & 61 \\
\hline \multirow[t]{6}{*}{ Clinical presentation (breast) ${ }^{\mathrm{e}}$} & Seroma & 266 & 58 & 302 & 53 \\
\hline & Breast swelling/pain & 135 & 30 & 150 & 26 \\
\hline & Capsular contracture & 69 & 15 & 73 & 13 \\
\hline & Peri-implant mass/lump & 82 & 18 & 94 & 16 \\
\hline & Others & 43 & 9 & 56 & 10 \\
\hline & Not specified & 105 & 23 & 147 & 26 \\
\hline \multirow[t]{3}{*}{ Anaplastic lymphoma kinase } & Positive & 0 & 0 & 0 & 0 \\
\hline & Negative & 229 & 50 & 255 & 45 \\
\hline & Not specified & 228 & 50 & 318 & 55 \\
\hline \multirow[t]{3}{*}{ CD30 status ${ }^{\oplus}$} & Positive & 215 & 47 & 246 & 43 \\
\hline & Negative & 0 & 0 & 0 & 0 \\
\hline & Not specified & 242 & 53 & 327 & 57 \\
\hline \multirow[t]{5}{*}{ Implant manufacturer } & Allergan includes McGhan, Inamed & 386 & 84 & 481 & 84 \\
\hline & Mentor & 36 & 8 & 38 & 7 \\
\hline & Sientra & 2 & 0.4 & 6 & 1 \\
\hline & Other manufacturer ${ }^{9)}$ & 5 & 1 & 6 & 1 \\
\hline & Unknown manufacturer & 28 & 6 & 42 & 7 \\
\hline \multirow[t]{3}{*}{ Reporter country: US or OUS ${ }^{\text {h) }}$} & US & 276 & 48 & 320 & 56 \\
\hline & OUS & 181 & 32 & 253 & 44 \\
\hline & Not specified & 0 & 0 & 0 & 0 \\
\hline
\end{tabular}

US, the United States; MDR, medical device report; ALCL, associated anaplastic large-cell lymphoma; OUS, outside the US.

a) Patients with bilateral breast implant (BIA)-ALCL are counted as two cases of BIA-ALCL. ${ }^{b}$ Percentage in terms of the total 457 MDRs. ${ }^{~}$ Percentage in

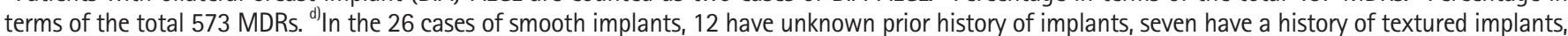
and seven have a history of prior implants with an unknown texture. There are no reports of cases associated with tissue expanders. ${ }^{e} M D R s$ sometimes list more than one clinical presentation, e.g., seroma and peri-implant mass/lump, in which two presentations were counted. " $\mathrm{CD} 30$ is a cell membrane protein associated with diagnosis of classic Hodgkin's lymphoma and BIA-ALCL. ${ }^{~ g}$ Other manufacturers include: Bristol Myers Squib, Nagor, Polytech Silimed, Silimed, and Sientra/Silimed. "ISS/OUS is counted as the recorded reporter's country in the MedWatch form, or if the event was noted to be from a foreign source in box G3 of the MedWatch form. Please note that the reporter country may not reflect the country where the event occurred or the country where the device is marketed.

Adapted from the materials of U.S. Food and Drug Administration [6]. 
textured breast implants and BIA-ALCL. They reported that BIA-ALCL develops only with textured implants, with an incidence rate of 2.03 per million per year, which is 67.6 times higher than that of primary ALCL of the breast in the general population. Lifetime prevalence was estimated to be 33 per million (one per 30,000) women with textured breast implants [8]. In 2017, a study from Australia and New Zealand reported the highest incidence of BIA-ALCL. Fifty-six cases in total had been confirmed by 2017, including 26 new cases of BIA-ALCL diagnosed between January 2017 and April 2018, representing a 47\% increase in the number of confirmed cases. The estimated incidence has subsequently been revised from one in 300,000 to one in 1,000-10,000 patients [9]. The number of cases is increasing with the growing interest and recognition among physicians.

\section{Implant texture and manufacturer}

All clinical case reports have demonstrated a strong relationship between BIA-ALCL and textured breast implants. In 2015, Brody et al. [10] reviewed all current BIA-ALCL literature, analyzing 173 cases of the disease, and found that all patients with a known clinical history had received at least one textured surface implant. Additionally, there were no cases before the introduction of textured surface implants. Of the 573 US and global medical device reports of BIA-ALCL, 385 cases had a history of textured implants, 162 were not specified, and 26 had smooth implants. However, these 26 smooth implant cases either had a history of prior exposure to textured implant before revision surgery to smooth implants or no clinical history to review (Table 2) [6].

Magnusson et al. [11] investigated the implant-specific risks of BIA-ALCL with 110 implants in 81 patients in 2019. They reported that the implant-specific risk is 23.4 times higher with Silimed polyurethane (Silimed, Rio De Janeiro, Brazil) and 16.52 times higher with Biocell implants, compared with Siltex implants (Mentor, Santa Barbara, CA, USA). A total of 484 cases of the 573 (84.5\%) registered the US and global medical device reports had a history of Allergan implants. Of the 33 reported deaths, no information regarding the implant manufacturer was available for 20 of them; among the remaining 13, 12 had Allergan implants. This is the reason why MFDS ordered a ban on Biocell breast implants (Tables 1,2). The FDA recalled Allergan textured breast implants and expanders because of the higher rate of BIA-ALCL associated with Biocell breast implants.

\section{Etiology}

The etiology and process of BIA-ALCL development are not well understood, but it is likely a complex process involving multiple factors. However, it is related to textured implants, and chronic inflammation has been proposed as a potential etiologic factor and precursor to tumorigenesis. Various pathogenetic theories, including the immunologic hypothesis, tribology, and subclinical infection, have been proposed to explain the mechanism of chronic inflammation. The immunology hypothesis suggests that silicone particles released from the surface of textured implants generate foreign bodies, resulting in chronic inflammation [12]. According to the tribology hypothesis, aggressively textured implants cause delamination of the periprosthetic capsule and lead to the formation of a double capsule through mechanical tear stress [13], consequently causing unresolved inflammation, genetic instability, and activation of maladaptive homeostatic responses and dormant transcription factors [14]. The subclinical infection hypothesis was supported by studies carried out by $\mathrm{Hu}$ et al. [15] in 2015 . He compared the microbiological colonization of implant capsules between BIA-ALCL patients and patients with capsular fibrosis. The BIA-ALCL groups had a higher bacterial burden and a significantly different distribution of bacteria, predominated by the gram-negative pathogen Ralstonia pickettii.

\section{Clinical presentation}

The first and most common symptom of BIA-ALCL is unilateral or bilateral peri-implant fluid collection following aesthetic or reconstructive implantation with textured surface breast implants. It can be accompanied by breast swelling, asymmetry, or pain. Skin symptoms (e.g., inflammation, papules) and unilateral regional lymphadenopathy have been described [16]. B-type symptoms such as fever, lymphadenopathy, night sweating, and fatigue can be accompanied [17]. Most cases of BIA-ALCL are detected on average 7 to 10 years after implantation. However, there was one reported within 2 years, and another reported as late as 32 years after implantation [18]. In addition, there was one occurrence 2 months after the exchange of an implant [17]. Most cases are unilateral, but four cases of bilateral involvement have been reported in patients with bilateral breast implants [19]. Approximately $60 \%$ of patients present with malignant effusion, $17 \%$ with a mass, and $20 \%$ of patients present with both seroma and mass [20].

\section{Diagnosis}

Standardized diagnosis and management guidelines for BIA-ALCL have been established by the National Comprehensive Cancer Network (NCCN) [21]. BIA-ALCL should be suspected and evaluated for patients who develop spontaneous peri-implant fluid 
collection occurring more than 1 year after aesthetic or reconstructive implantation with a textured surface breast implant. Many patients with breast implants are likely to have a small amount of peri-implant fluid (5-10 mL) without symptoms. These are normal findings and do not require further evaluation. Ultrasonography is the best imaging method for detecting and defining any peri-implant fluid or mass. Suspicious fluid collections should be aspirated with a fine needle under ultrasonography guidance. A minimum of $10 \mathrm{~mL}$ (ideally $>50 \mathrm{~mL}$ ) of fluid should be collected to diagnose BIA-ALCL. A suspected mass requires a tissue biopsy. Specimens should be sent for cell morphology by cytology, immunohistochemistry, and flow cytometry [22-25]. BIA-ALCL is CD30 positive, epithelial membrane antigen positive, and ALK negative (Fig. 1). After histologic confirmation of BIA-ALCL, further lymphoma workup and staging are recommended.

Each case should ideally be discussed at a multidisciplinary team conference consisting of oncologists, radiologists, pathologists, and plastic surgeons. Routine laboratory work should include complete blood cell count with differential, comprehensive metabolic panel, and lactate dehydrogenase levels. Positron emission tomographic (PET) and computed tomographic (CT) scans are beneficial for demonstrating associated capsular masses, chest wall involvement, regional lymphadenopathy, and/or distant organ metastasis [10].

\section{Preoperative evaluation/staging}

There are two main staging systems for BIA-ALCL, the Lugano modification of the Ann Arbor staging system and the BIA-ALCL tumor, node, and metastasis (TNM) staging system. The traditional staging system for non-Hodgkin lymphoma is the Lugano modification of the Ann Arbor staging system, which has been used in many previous reports. In this system, stage IE disease is limited to a single extranodal (E) site such as the breast or implant capsule, whereas stage IIE disease is defined as an extranodal disease with spread to or involvement of local lymph nodes [26]. Most patients with BIA-ALCL have an early-stage disease, either stage IE (83\%-84\%) or stage IIE (10\%-16\%), while a few of them (0\%-7\%) fall into stage IV disease with this system $[21,27,28]$. Because of the unique characteristics of BIA-ALCL that behaves like a solid tumor rather than a liquid tumor and that the Ann Arbor staging system does not consider capsular invasion, $\mathrm{NCCN}$ is now using the TNM staging system modeled after the American Joint Committee on Cancer TNM [27]. However, the TNM classification describes BIA-ALCL as a spectrum of disease from stage IA (35\%-70\%, effusion only), IB (3\%-11\%), IC ( $8 \%-13 \%)$, IIA $(8 \%-25 \%)[7,14,21]$, IIB (3\%-5\%), and III (3\%-9\%) to IV (1\%$2 \%)[7,27]$.

\section{Treatment}

The most important factors for the treatment of BIA-ALCL are timely diagnosis and complete surgical excision [27]. The goals of surgery are complete removal of the implant, including the surrounding fibrous capsule and any associated mass. Complete surgical excision prolongs overall survival and event-free survival compared with all other therapeutic interventions. In subpectoral implant placement, adherence to the rib cage can make complete resection difficult, while an injection of tumescent solution facilitates complete excision. In this case, care must be taken to avoid pneumothorax. The effect of local seeding of malignant seroma on capsulectomy is not yet clear. However, clinically, this has not been observed to influence the recurrence rate. In cases presenting with a mass, complete excision of the mass with a negative margin is es-
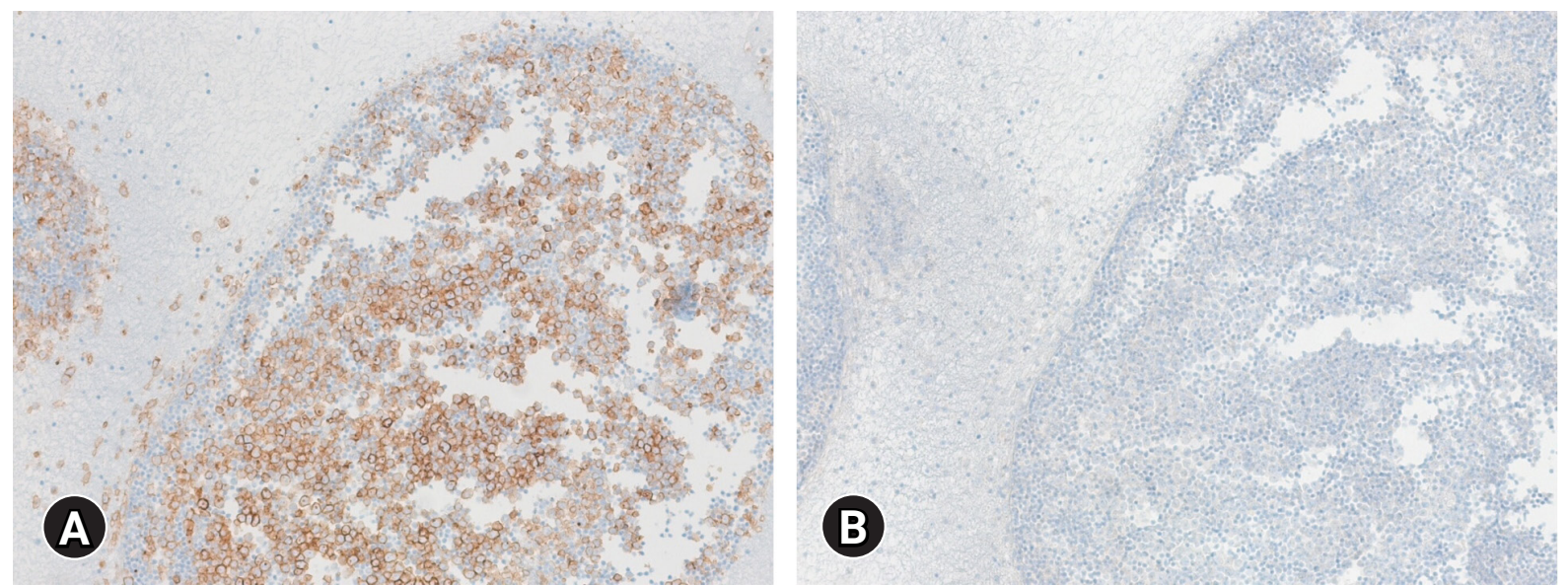

Fig. 1. (A) Immunohistochemistry for CD30 highlights the membranes of neoplastic cells. (B) The neoplastic cells are negative for anaplastic lymphoma kinase (ALK) (immunohistochemical stain, x100 [A] and [B]). 
sential. At present, there is no clear role for radical mastectomy or sentinel lymph node biopsy. Full axillary dissection has rarely been used for the gross involvement of multiple lymph nodes. According to the NCCN guidelines, an estimated $2 \%$ to $4 \%$ of patients develop bilateral disease, and therefore surgeons may consider the removal of the contralateral implant. The rate of disease events and recurrence is 2.6-fold higher for stage II disease and 2.7-fold higher for stage III disease than for stage I disease [26]. The recurrence rate following complete surgical excision is $14.3 \%$ for patients with $\mathrm{T} 4$ disease compared with $0 \%$ for patients with $\mathrm{T} 1$ to $\mathrm{T} 3$ disease [27].

\section{Adjuvant therapy}

There are no established treatment protocols for stage II or more advanced, disseminated, and recurrent cases after complete resection. Therefore, treatment protocols for primary cutaneous and systemic ALCL are generally used. Radiation therapy with 24 to $36 \mathrm{~Gy}$ is suggested for patients with local residual disease, positive margins, or unresectable disease with chest wall invasion like the cutaneous ALCL [29]. Systemic therapy combined with anthracycline-based chemotherapy or brentuximab vedotin is used for stage II or more advanced or disseminated state [30-35].

\section{Follow-up}

Patients showing complete response to treatment can be monitored with history and physical exanimation every 3 to 6 months for 2 years and then as clinically indicated. Monitoring may include CT or PET/CT scans every 6 months for 2 years and then only if clinically indicated.

\section{Conclusion}

As of 2020, three cases of BIA-ALCL have been reported in Korea. This means that Korea is no longer a safe country from BIA-ALCL, and more patients may be reported. Every symptomatic peri-implant fluid collection for more than 1 year after textured surface implantation with aesthetic or reconstructive surgery should be evaluated for BIA-ALCL.

\section{Notes}

\section{Conflicts of interest}

No potential conflict of interest relevant to this article was reported.

\section{Acknowledgments}

I thank Professor Il-Kug Kim, Department of Plastic and Reconstructive Surgery, Yeungnam University College of Medicine, for providing the photographs.

\section{ORCID}

Jun-Ho Lee, https://orcid.org/0000-0002-0062-6420

\section{References}

1. Ministry of Food and Drug Safety; Korean Society of Plastic and Reconstructive Surgeons. The report of breast implant associated anaplastic large cell lymphoma (BIA-ALCL) in Korea [Internet]. Cheongju, KR: Ministry of Food and Drug Safety; 2019 [cited 2020 May 15]. https://www.mfds.go.kr/brd/ m_99/view.do?seq $=43641$.

2. Gye SH. Unfinished fear for Allergan artificial breast: the third rare cancer in Korea occurs [Internet]. Seoul, KR: Yonhap News; 2020 [cited 2020 Oct 15]. https://www.yna.co.kr/view/ AKR20201004030000017? input $=1195 \mathrm{~m}$.

3. Center for Devices and Radiological Health $(\mathrm{CDRH})$. Anaplastic large cell lymphoma (ALCL) in women with breast implants: preliminary FDA findings and analyses [Internet]. Silver Spring (MD): CDRH; 2011 [cited 2020 May 15]. https:// www.nvpc.nl/uploads/stand/NVPC110126DOC-FN-ASPS Final_ALCL_White_Paper_Clean_Version_1-18-1177.pdf.

4. Swerdlow SH, Campo E, Pileri SA, Harris NL, Stein H, Siebert $\mathrm{R}$, et al. The 2016 revision of the World Health Organization classification of lymphoid neoplasms. Blood 2016;127:237590.

5. Keech JA Jr, Creech BJ. Anaplastic T-cell lymphoma in proximity to a saline-filled breast implant. Plast Reconstr Surg 1997;100:554-5.

6. U.S. Food and Drug Adiministration (FDA). Medical device reports of breast implant-associated anaplastic large cell lymphoma [Internet]. Silver Spring (MD): FDA; 2020 [cited 2020 May 15]. https://www.fda.gov/medical-devices/breast-implants/medical-device-reports-breast-implant-associated-anaplastic-large-cell-lymphoma.

7. de Jong D, Vasmel WL, de Boer JP, Verhave G, Barbé E, Casparie MK, et al. Anaplastic large-cell lymphoma in women with breast implants. JAMA 2008;300:2030-5.

8. Doren EL, Miranda RN, Selber JC, Garvey PB, Liu J, Medeiros LJ, et al. U.S. epidemiology of breast implant-associated anaplastic large cell lymphoma. Plast Reconstr Surg 2017;139:104250 .

9. Loch-Wilkinson A, Beath KJ, Knight RJ, Wessels WL, Magnus- 
son M, Papadopoulos T, et al. Breast implant-associated anaplastic large cell lymphoma in Australia and New Zealand: high-surface-area textured implants are associated with increased risk. Plast Reconstr Surg 2017;140:645-54.

10. Brody GS, Deapen D, Taylor CR, Pinter-Brown L, House-Lightner SR, Andersen JS, et al. Anaplastic large cell lymphoma occurring in women with breast implants: analysis of 173 cases. Plast Reconstr Surg 2015;135:695-705.

11. Magnusson M, Beath K, Cooter R, Locke M, Prince HM, Elder E, et al. The epidemiology of breast implant-associated anaplastic large cell lymphoma in Australia and New Zealand confirms the highest risk for grade 4 surface breast implants. Plast Reconstr Surg 2019;143:1285-92.

12. Santanelli di Pompeo F, Sorotos M. EURAPS editorial: BIA-ALCL, a brief overview. J Plast Reconstr Aesthet Surg 2018;71:785-7.

13. Giot JP, Paek LS, Nizard N, El-Diwany M, Gaboury LA, Nelea $\mathrm{M}$, et al. The double capsules in macro-textured breast implants. Biomaterials 2015;67:65-72.

14. Colotta F, Allavena P, Sica A, Garlanda C, Mantovani A. Cancer-related inflammation, the seventh hallmark of cancer: links to genetic instability. Carcinogenesis 2009;30:1073-81.

15. Hu H, Jacombs A, Vickery K, Merten SL, Pennington DG, Deva AK. Chronic biofilm infection in breast implants is associated with an increased T-cell lymphocytic infiltrate: implications for breast implant-associated lymphoma. Plast Reconstr Surg 2015;135:319-29.

16. Tardío JC, Granados R. Axillary lymphadenopathy: an outstanding presentation for breast implant-associated ALK-negative anaplastic large cell lymphoma. Int J Surg Pathol 2015;23: 424-8.

17. Carty MJ, Pribaz JJ, Antin JH, Volpicelli ER, Toomey CE, Farkash EA, et al. A patient death attributable to implant-related primary anaplastic large cell lymphoma of the breast. Plast Reconstr Surg 2011;128:112e-118e.

18. Ebner PJ, Liu A, Gould DJ, Patel KM. Breast implant-associated anaplastic large cell lymphoma, a systematic review and indepth evaluation of the current understanding. J Surg Oncol 2019;120:573-7.

19. Kricheldorff J, Fallenberg EM, Solbach C, Gerber-Schäfer C, Rancsó C, Fritschen UV. Breast implant-associated lymphoma. Dtsch Arztebl Int 2018;115:628-35.

20. Leberfinger AN, Behar BJ, Williams NC, Rakszawski KL, Potochny JD, Mackay DR, et al. Breast implant-associated anaplastic large cell lymphoma: a systematic review. JAMA Surg 2017; 152:1161-8.

21. Clemens MW, Horwitz SM. NCCN consensus guidelines for the diagnosis and management of breast implant-associated anaplastic large cell lymphoma. Aesthet Surg J 2017;37:285-9.

22. Wohlgemuth FB, Brasil MB, d'Acampora AJ. Risk of breast implant-associated anaplastic large cell lymphoma in patients submitted to breast implantation: a systematic review. Breast J 2019;25:932-7.

23. Wu D, Allen CT, Fromm JR. Flow cytometry of ALK-negative anaplastic large cell lymphoma of breast implant-associated effusion and capsular tissue. Cytometry B Clin Cytom 2015;88: $58-63$.

24. Talagas M, Uguen A, Charles-Petillon F, Conan-Charlet V, Marion V, Hu W, et al. Breast implant-associated anaplastic large-cell lymphoma can be a diagnostic challenge for pathologists. Acta Cytol 2014;58:103-7.

25. Kim B, Predmore ZS, Mattke S, van Busum K, Gidengil CA. Breast implant-associated anaplastic large cell lymphoma: updated results from a structured expert consultation process. Plast Reconstr Surg Glob Open 2015;3:e296.

26. Cheson BD, Fisher RI, Barrington SF, Cavalli F, Schwartz LH, Zucca E, et al. Recommendations for initial evaluation, staging, and response assessment of Hodgkin and non-Hodgkin lymphoma: the Lugano classification. J Clin Oncol 2014;32:305968.

27. Clemens MW, Medeiros LJ, Butler CE, Hunt KK, Fanale MA, Horwitz S, et al. Complete surgical excision is essential for the management of patients with breast implant-associated anaplastic large-cell lymphoma. J Clin Oncol 2016;34:160-8.

28. Miranda RN, Aladily TN, Prince HM, Kanagal-Shamanna R, de Jong D, Fayad LE, et al. Breast implant-associated anaplastic large-cell lymphoma: long-term follow-up of 60 patients. J Clin Oncol 2014;32:114-20.

29. Estes CF, Zhang D, Reyes R, Korentager R, McGinness M, Lominska C. Locally advanced breast implant-associated anaplastic large-cell lymphoma: a case report of successful treatment with radiation and chemotherapy. Front Oncol 2015;5:26.

30. Johnson L, O’Donoghue JM, McLean N, Turton P, Khan AA, Turner SD, et al. Breast implant associated anaplastic large cell lymphoma: the UK experience: recommendations on its management and implications for informed consent. Eur J Surg Oncol 2017;43:1393-401.

31. Duvic M, Tetzlaff MT, Gangar P, Clos AL, Sui D, Talpur R. Results of a phase II trial of brentuximab vedotin for CD30+ cutaneous T-cell lymphoma and lymphomatoid papulosis. J Clin Oncol 2015;33:3759-65.

32. Kim YH, Tavallaee M, Sundram U, Salva KA, Wood GS, Li S, et al. Phase II investigator-initiated study of brentuximab vedotin in mycosis fungoides and Sézary syndrome with variable CD30 
expression level: a multi-institution collaborative project. J Clin Oncol 2015;33:3750-8.

33. Prince HM, Kim YH, Horwitz SM, Dummer R, Scarisbrick J, Quaglino P, et al. Brentuximab vedotin or physician's choice in CD30-positive cutaneous T-cell lymphoma (ALCANZA): an international, open-label, randomised, phase 3, multicentre trial. Lancet 2017;390:555-66.
34. Younes A, Bartlett NL, Leonard JP, Kennedy DA, Lynch CM, Sievers EL, et al. Brentuximab vedotin (SGN-35) for relapsed CD30-positive lymphomas. N Engl J Med 2010;363:1812-21.

35. Pro B, Advani R, Brice P, Bartlett NL, Rosenblatt JD, Illidge T, et al. Brentuximab vedotin (SGN-35) in patients with relapsed or refractory systemic anaplastic large-cell lymphoma: results of a phase II study.J Clin Oncol 2012;30:2190-6. 